\title{
Predictive Fuzzy model for a First Year Design Oriented Project Based Learning course
}

\author{
Raj Jaiswal \\ Dundalk Institute of Technology \\ Ireland \\ Rohanie Maharaj \\ The University of Trinidad and Tobago \\ Trinidad and Tobago Festus \\ Addo-Yobo \\ The University of Trinidad and Tobago \\ Trinidad and Tobago Sarim Al- \\ Zubaidy \\ The University of Trinidad and Tobago \\ Trinidad and Tobago
}

\begin{abstract}
The first year of an engineering program provides a chance for academic staff to prepare students not only for their degree but also to the world of work and to instill in them the drive to become motivated, lifelong learners and be independent. An Engineering Systems Design 1 course was developed for the first year to introduce students to the world of engineering through a mix of design projects, interactive workshops and lectures. The paper outlines the experience and the impact that introducing the above on student's engagement and progression. Comparison with other first-year courses is also shown. A proposed predictive fuzzy model for all firstyear courses is outlined. Results show that prediction based on the fuzzy model is highly correlated with the actual students' grades and therefore, could be used as a predictive tool.
\end{abstract}

Keywords: Engineering System Design, Prediction model, Problem-Based Learning, Project-Based Learning, Fuzzy- Based Model

\section{Index of notation}

EM1 Engineering Mathematics 1 module (MTCA3001)

ES Engineering Science Module (MTCS3002)

EM Engineering Materials and Hardware (MTCA3003)

EP Electrical Principals (MTCM3004) 
EE Introduction to Electrical Engineering (MTCM3005)

ESD1 Engineering System Design 1 (MTCS3007)

i Index of a module

$r \quad$ Index of corresponding fuzzy score

r' regression coefficient

\section{Linguistic variables}

E Engaging of students during lectures and

tutorial 0 Overall skill development I Interests

of Students

S Feedback on Students Progress

P Students Performance 


\section{Introduction}

When establishing the Military Technological College (MTC), it was recognized the importance of developing effective and engaging teaching and learning strategies, that are more inductive and student-centric, moving away from the old engineering instructional strategies that are mainly deductive. Despite evidence that these deductive practices in engineering education suffer from serious limitations, student-centric learning has found little traction in many parts of the developing world. To prepare students to face the many divergent and multi-disciplinary problems as professional engineers upon their employment, core concepts of project based learning was introduced from the foundation year curriculum at FHEQ (Framework for Higher Education Qualifications) Level 3. As proposed [Connor et al, 2015], the need for systems to be investigated as wholes, which requires cross-disciplinary approach and new conceptual principles and tools, were well integrated into learning and teaching strategies, to support students to improve their performance and ability in solving real world problems. Project learning and engineering design should provide an appropriate environment for reflective thinking and adopting innovative ways of thinking.

ESD1 is the introductory first-year course developed to engage the students in reflective system thinking approach. As shown in figure 1 below, this course is delivered in the third trimester. This is a core course taken by all students at MTC in the disciplines of aeronautical, civil, marine, systems engineering and quantity surveying.

\section{Figure 1 Delivery of ESD1}

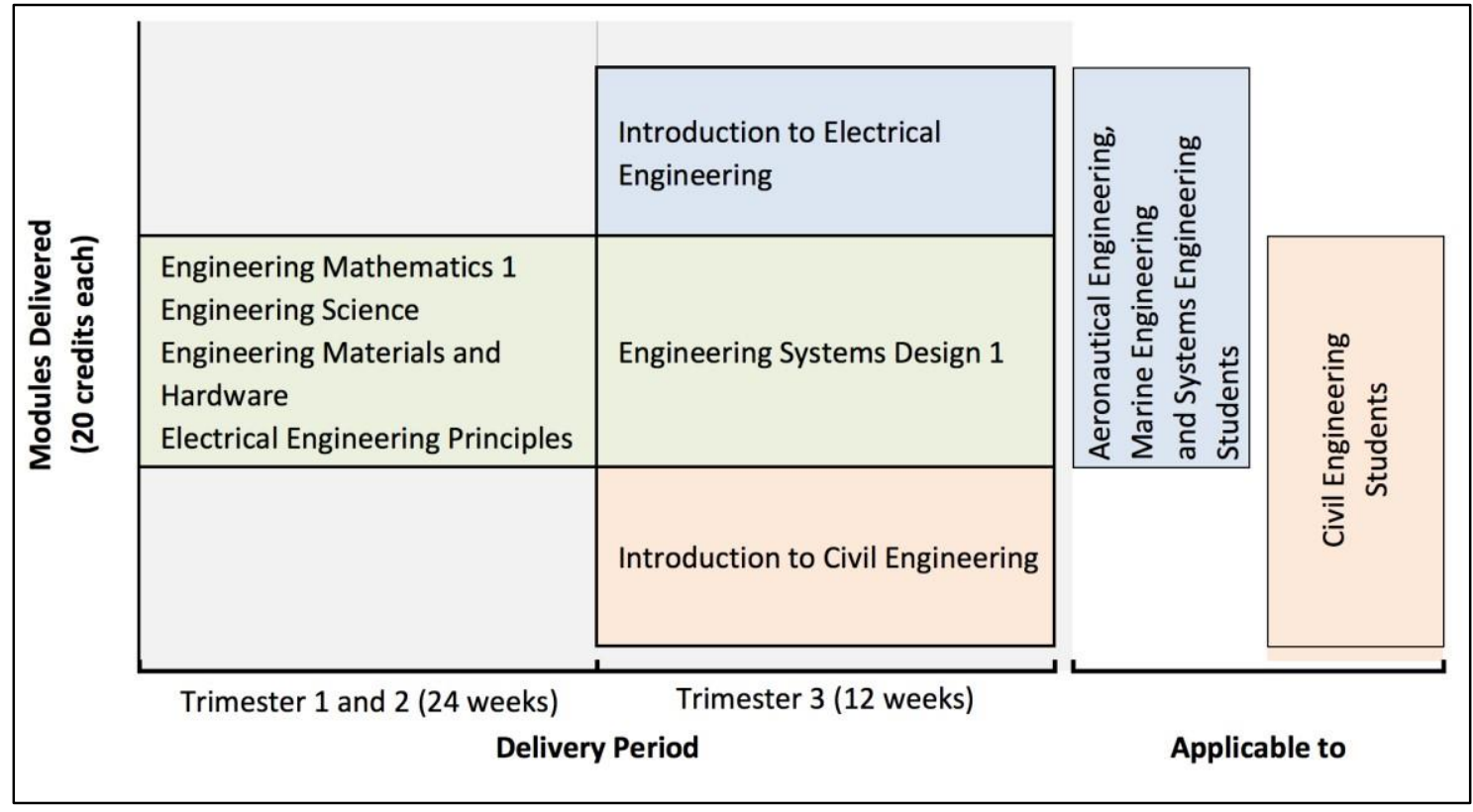

Students are exposed to various elements of Project Based learning [Albanese et al, 1993] through a combination of Interactive lectures and tutorials, initially geared to projects, workshop activities, individual concepts, design and practical activity. After six-week period, students demonstrate their work through a poster design. The MATLAB workshop helps the students to model or simulate and test their design. The final work is assessed through a project presentation as shown in Figure 2 below. 
Figure 2 Schedule of ESD1

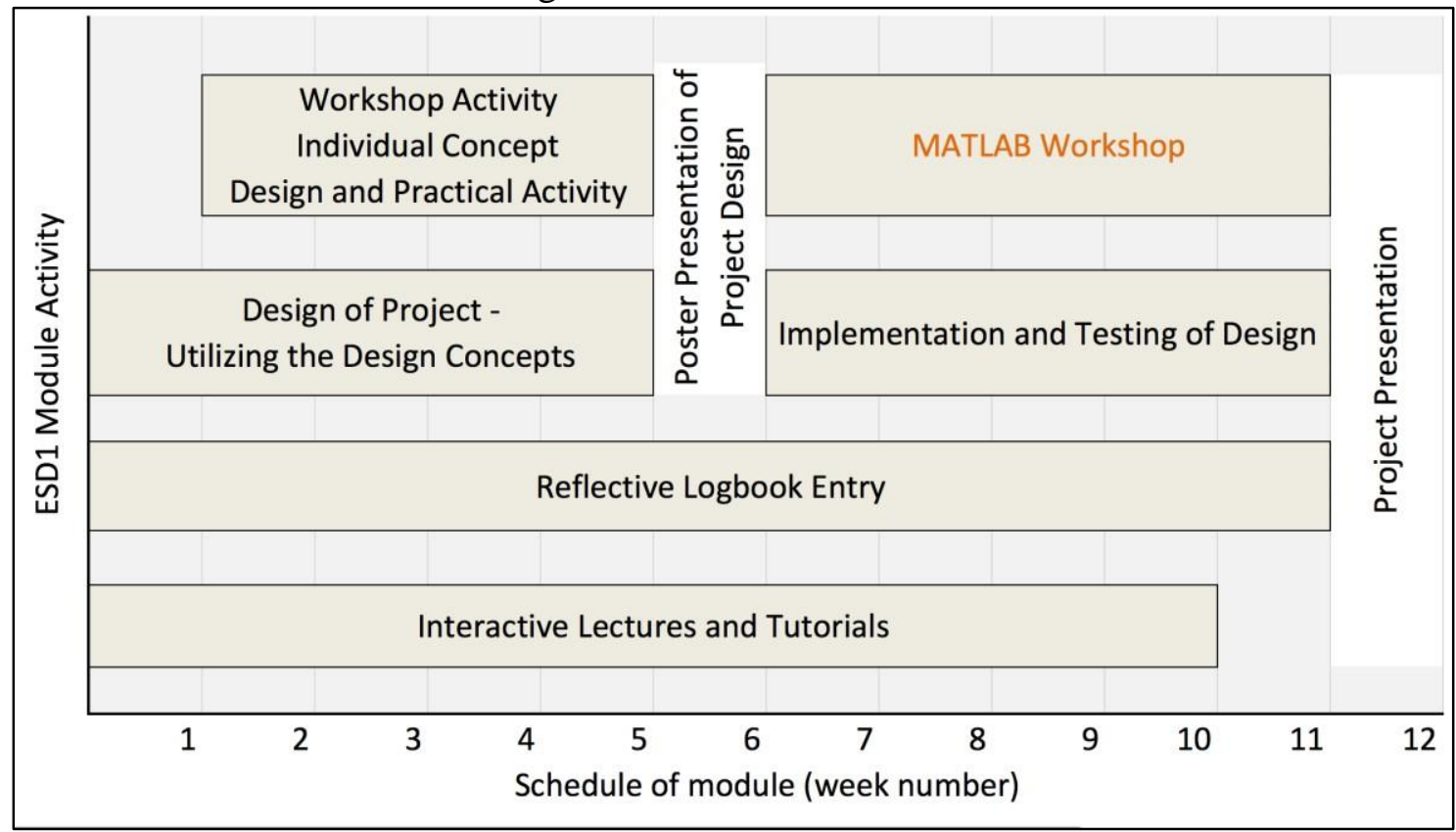

The core concepts with several elements of project based learning [Barrows, 1996; Wilkinson, 2005] and reflective thinking exposed in this course are further enforced through the Engineering Design 2 (ESD2) course in the following year at FHEQ level 4. ESD2 applies knowledge gained to solve more complex design challenges, promoting their ability to think reflectively [Sabag, 2014] should be noted that the engineering design thread in the programme run through all the four years of study as shown in the Figure 3 below.

Figure 3 Design elements through the four-year programme 


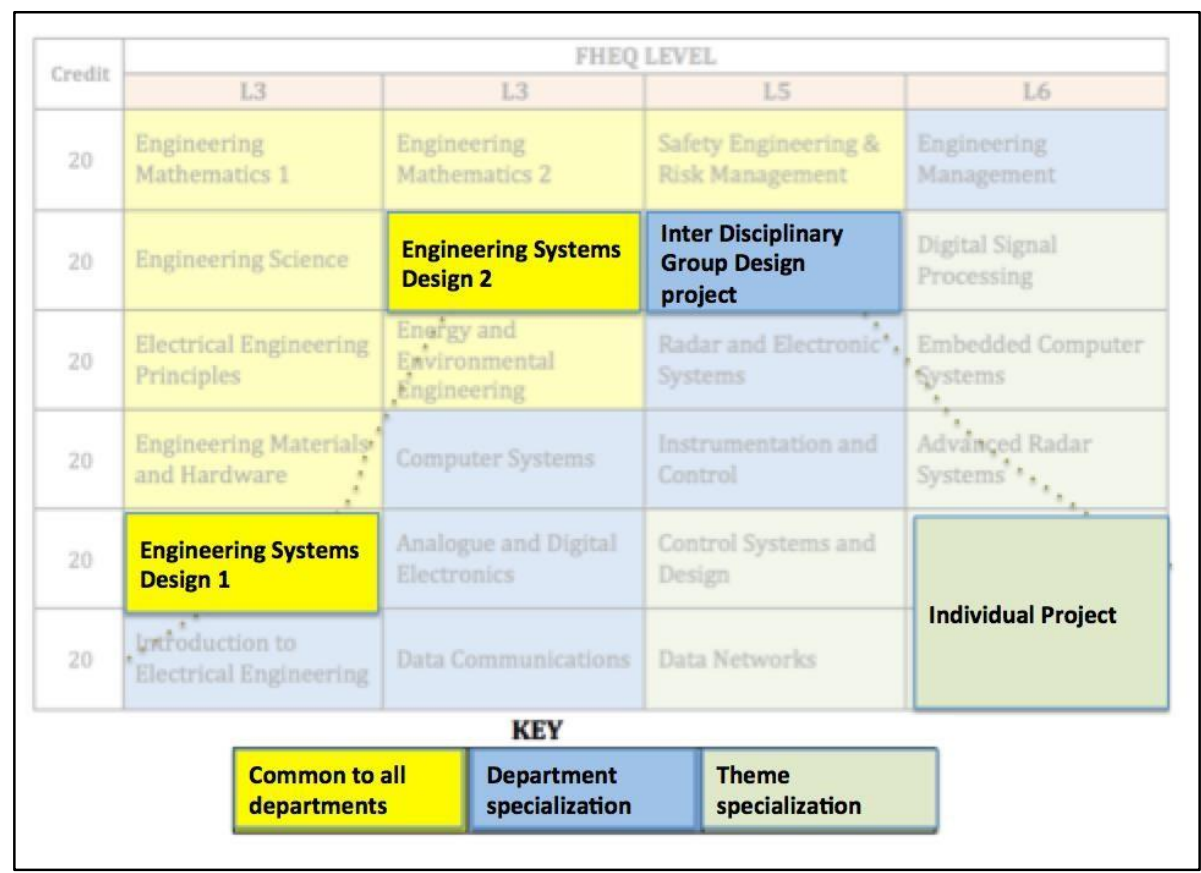

ESD1 objective is to develop engineering practice with a strong emphasis on design, safety, ethics and the environment. Students work in teams on practical engineering design tasks. The subject is structured in three phases; engineering challenges, professionalism and robotics (programming and flow charts), focusing on problems solving, teamwork, communications including report writing and presentations.

Finally, students are engaged in an intra-disciplinary group and individual projects at FHEQ levels 5 and 6 respectively, with the purpose to further develop their understanding of the challenges and problems that come from trying to reconcile multiple disciplinary perspectives and values on a single problem. The courses integrate further the skills and knowledge gained within their programmes and is a vehicle for their further development in a multidisciplinary context. This will help them to understand how to organize these in a practical, commercial and engineering context. It is designed as a student-centred course and by working within an intra-disciplinary group; student recognizes the roles and responsibilities of others involved in the design process. In the following section, a summary of how all first year engineering courses are designed and delivered, this is followed by a detailed description of the proposed predictive model of students performance based on the different aspects of course design. A comparison of prediction and actual students' grades is then outlined.

\section{Comparison of ESD1 with other courses}

The information highlights on how each of the six courses of the first year of an Engineering degree was delivered is shown in table 1 (during the academic year 20142015). For example, EM1 has a total of 72 hours of lectures and tutorials well supported by 12 hours of practical sessions. However, the practical sessions in EM1 do not offer hand-on experience unlike other courses, but EM1 is taught within engineering context and in an applied setting. Last two columns indicate the contribution of coursework and a final exam respectively for each course. It is useful to note two 
important features in the delivery and assessment of ESD1. In contrast with other courses, first, ESD1 required students to write weekly logbook entry for their reflective journal and second, students are assessed through a series of coursework without final written exam.

\section{$\underline{\text { Table } 1 \text { Comparison of all the courses delivered in level } 3 \text { Engineering Program }}$}

Lectures

Practical or Skill

Courses
Hands-on
Weekly and

Course Final

Reflective

Tutorial Development (Hrs.) Experience -work Exam (Hrs.) Journal

\begin{tabular}{cccccccc}
\hline EM1 & 72 & Practical & 12 & No & No & $30 \%$ & $70 \%$ \\
\hline ES & 60 & Practical/Lab & 24 & Yes & No & $50 \%$ & $50 \%$ \\
\hline EM & 72 & Practical/Lab & 36 & Yes & No & $40 \%$ & $60 \%$ \\
\hline EP & 72 & Practical/Lab & 40 & Yes & No & $40 \%$ & $60 \%$ \\
\hline EE & 72 & Practical/Lab & 55 & Yes & No & $40 \%$ & $60 \%$ \\
\hline ESD1 & 38 & $\begin{array}{c}\text { Workshop } \\
\text { Activities }\end{array}$ & 42 & Yes & Yes & $100 \%$ & $0 \%$ \\
\hline
\end{tabular}

\section{Predictive Fuzzy Model}

Fuzzy modeling [Zadeh, 1994; Stachowicz et al, 1987; Pedrycz, 1996 ; Babuska, 1998] is a process by which we use fuzzy logic to model real-life input/output productive systems that can be defined by fuzzy sets. Fuzzy model mainly operates on information granules such as fuzzy sets and fuzzy restrictions on linguistic variables that completely define the modeled system; a fuzzy model can predict a target value thus it can be used to compare with actual data. The proposed predictive fuzzy model that can predict the students' performance, $\mathrm{P}$, based on an assumed set of linguistic variables, E, O , I and S, such that $\mathrm{P}$ has a functional dependence on them, which can be formulated as:

$$
f:(E, O, I, S) \rightarrow P
$$

\subsection{Linguistic Variables}

A linguistic variable [ Zadeh, 1975] is defined by a linguistic expression using one or more words and can take both linguistic and numerical values. It is typically used to give a mathematical representation of semantic concepts that comprise of more than one term (commonly known as fuzzy set). This process of grouping the values into a fuzzy set is known as Fuzzy classification [Abonyi et al, 2000]. A Fuzzy score is a numerical value assigned to the members of fuzzy set based on degree of membership. The degree of membership (mapping between the fuzzy set value and the numerical value $([0,1])$ can be defined by a propositional function. In this paper, we have used a different propositional function to determine the degree of membership for each fuzzy set.

In the proposed model, four linguistic variables, namely, E, O, S and I are considered to model and predict the students' performance, P. Each of these linguistic variables is 
defined by a set of fuzzy restrictions. A fuzzy restriction can be seen as a constraint for a given linguistic variable. Table 2 below indicates the column-wise listing of the four linguistic variables and the corresponding fuzzy restrictions on which the linguistic variables are modeled. For example, the linguistic variable, $\mathrm{I}$, is modeled using, $r$, where $\mathrm{r} \in\{\mathrm{a}, \mathrm{w}, \mathrm{k}\}$.

The classification of the fuzzy set is determined based on the fuzzy restrictions on the linguistic variables. Thereafter, a fuzzy score is evaluated based on the degree of membership of the fuzzy set. Finally, the students' performance is calculated by taking the cartesian product of the fuzzy scores of the four linguistic variables. This is based on the assumption that all the fuzzy sets that define the given linguistic variables are independent of each other. We further test the performance of our model by comparing it with actual results of the students for each course. In the following section a brief description on how each linguistic variable is modeled using subsequent descriptive figures and populated tables.

Table 2 Linguistic Variables and corresponding Fuzzy Restrictions

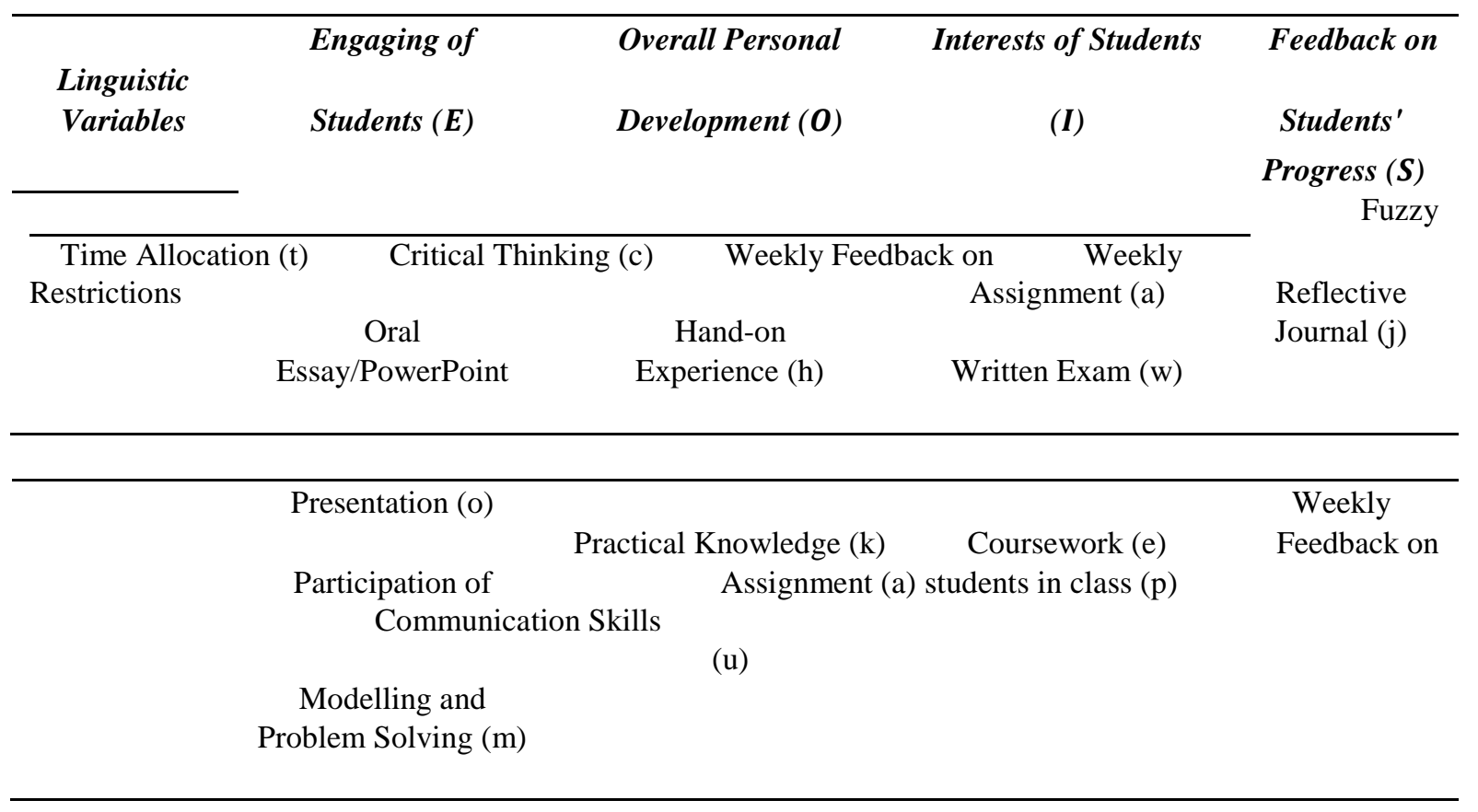

\subsection{Engaging of Students in Lectures and Tutorials, $E$}

In general, engineering students learn through engaging with lecturers and discussions within the class. Hence, optimizing the effectiveness of lectures or tutorials for maximum engagement of students would improve students learning. Linguistic variable, E, is to measure the students' engagement during lectures and tutorials based on various fuzzy restrictions including students participation in class, time allocation and discussion of problem solving techniques such as mathematical modeling. Oral and Essay presentation of definitions and other course contents are also used in traditional teaching methods where students' engagement in class is very limited. For this, we use the complement of the fuzzy score to measure, E. 
Figure 4 demonstrates the hierarchal structure of linguistic variables, E. The contents of oval shape in the center indicate the linguistic variable. Fuzzy restrictions, $r$ where $r \in\{t$, $\mathrm{o}, \mathrm{p}, \mathrm{m}\}$, can be seen in rectangle-shaped boxes attached to the oval shape with an arrow ૫. Thin arrows indicate to the numerical values assigned for each course based on the fuzzy restrictions on E. Course acronyms are indicated on the thin arrows for clear viewing. The corresponding fuzzy set values are shown at the end of the thin arrow. The mapped fuzzy scores corresponding to the fuzzy restrictions for respective courses are encircled and placed close to the thin arrows. The calculated Fuzzy scores for E, is given in the Table 3.

Figure 4 Hierarchical structure of linguistic variable E

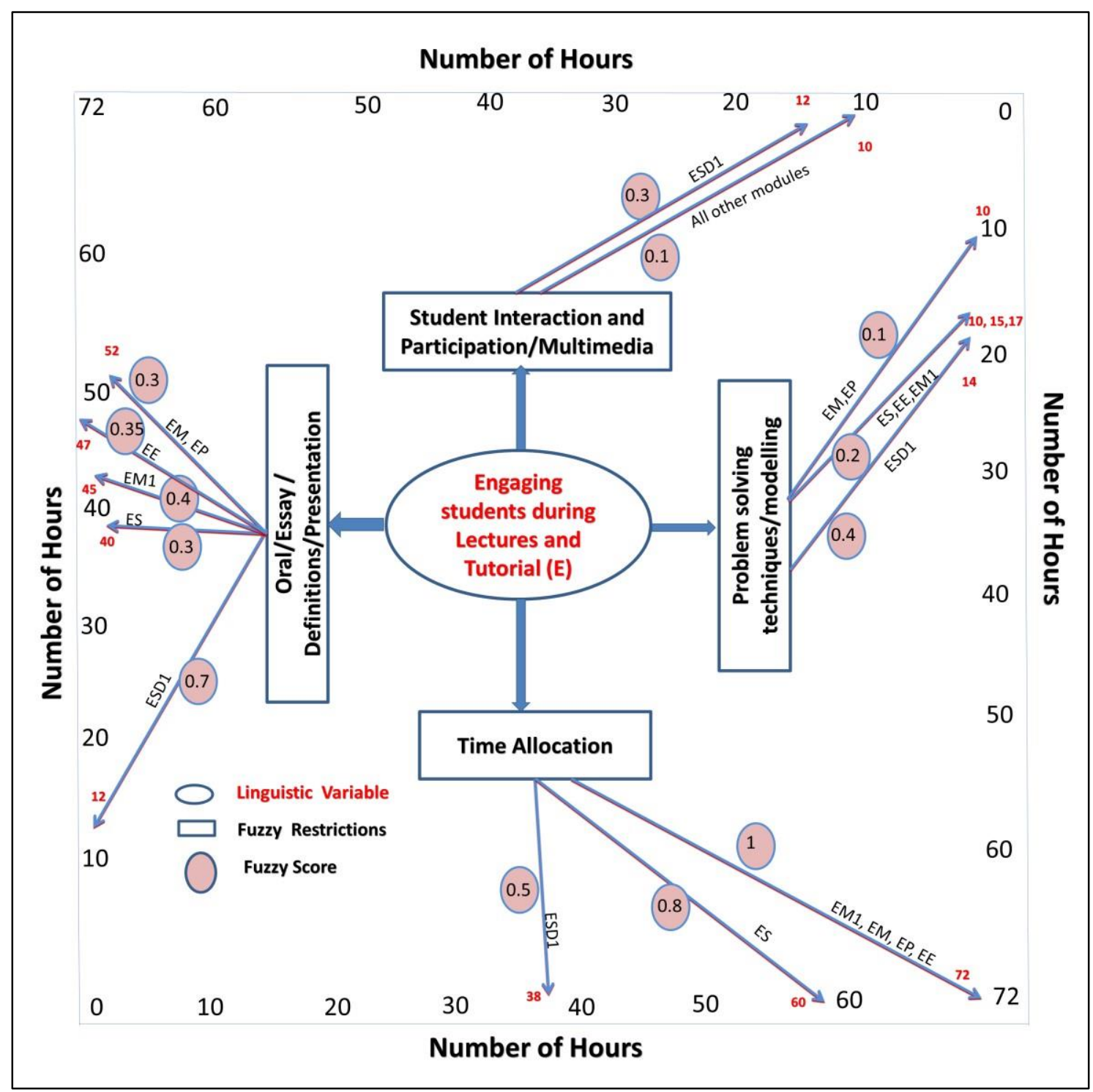

Table 3 Summary of fuzzy scores corresponding to the linguistic variable, $E$

$\begin{array}{llllllll}\text { Linguistic Variable }(E) & \text { EM1 } & E S & E M & E P & E E & \text { ESD1 } & \text { Formula }\end{array}$


Oral/Essay/ PowerPoint/ Definition $\left(o_{i}\right)$ Interaction/ Participation of students/Multimedia (Modelling and

Problem Solving methods $\left(m_{i}\right)$

Let the time allotted, fuzzy restriction, for each course for lecture and tutorials $\begin{array}{llll}10 & 10 & 15 & 14\end{array} \quad F_{m i}=$ be $t_{i}$. Similarly $o_{i}, p_{i}$ and $\mathrm{m}_{\mathrm{i}}$ represents

\begin{tabular}{|c|c|c|c|c|c|c|c|}
\hline & $(i=1)$ & $(i=2)$ & $(i=3)$ & $(i=4)$ & $(i=5)$ & $(i=6)$ & Used \\
\hline $\begin{array}{l}\text { Time allotted for each } \\
\text { course }\end{array}$ & 72 & 60 & 72 & 72 & 72 & 38 & $t_{i}$ \\
\hline$t i$ & 1 & 0.8 & 1 & 1 & 1 & 0.5 & \\
\hline$\frac{F_{o i}}{\left(p_{i}\right)}$ & 0.4 & 0.3 & & & & & other \\
\hline$F$ & 0.1 & 0.1 & 0.1 & 0.1 & 0.1 & 0.3 & \\
\hline$F_{m i}$ & 0.2 & 0.2 & 0.1 & 0.1 & 0.2 & 0.4 & \\
\hline
\end{tabular}

restrictions of $\mathbf{E}$ such that,

$$
\mathrm{t}_{\mathrm{i}}=\mathrm{o}_{\mathrm{i}}+\mathrm{p}_{\mathrm{i}}+\mathrm{m}_{\mathrm{i}}
$$

The formula used column in table 3 contains the expression to calculate the fuzzy score for each fuzzy restriction. As mentioned earlier, the time spend for Oral/Essay lightly impact engagement with students hence, the complement of the calculated score is considered. $\mathrm{F}_{\mathrm{oi}}, \mathrm{F}_{\mathrm{pi}}$, and $\mathrm{F}_{\mathrm{mi}}$ are the fuzzy scores for fuzzy restrictions as indicated in the respective rows in the table.

$$
\boldsymbol{E}_{\boldsymbol{i}}=\bigcup_{r} F_{t i} F_{r i}
$$

$$
\text { where } r \in\{o, p, m\}
$$

Please note that each of the fuzzy score of $r \in\{o, p, m\}$ are mutually exclusive, hence a union of fuzzy scores can be used to calculate each $\boldsymbol{E}_{\boldsymbol{i}}$.

\subsection{Overall Skill Development}

With the recent and often accelerated technological advancement and globalization of knowledge, there is a constant need to produce engineers who can clearly define and tackle real-life multidisciplinary engineering problems with innovations, critical thinking and self-directed learning [Woods et al, 2000]. Subsequently, it is also important for the engineers to convey ideas and complex concepts in a simple manner. This necessitates 
the need to encourage engineering schools and colleges to integrate activities within curricula to enhance overall students' skills development such as transferrable skills, entrepreneurship, teamwork, etc.. Skills development is an important aspect of for an individual personal and professional prosperity [McAdams et al, 2010].

Typically, in engineering, practical laboratories and interactive workshops are conducted with an aim of helping students to consolidate their theoretical knowledge in a laboratory environment and thus hone their overall engineering skills. The linguistic variable, $O$, is used to measure the students' overall skills development based on various fuzzy restrictions including critical thinking, hand-on experience, practical knowledge and communication skills. With the exception of ESD1, practical and labs were conducted for students to gain hands-on experience on the equipment and computer aided tools to solve a given problem. However, in these courses, students were not given much exposure to solve real life problems. In contrast, ESD1 conducted workshops to implement a project based learning or problem based learning in a supportive environment.

Figure 5 gives the hierarchal structure of linguistic variables, $\boldsymbol{O}$. Fuzzy restrictions can be defined by the following set where $r \in\{u, k, c, h\}$. The fuzzy set values such as like, probably are indicated at the arrow end of thin arrows for each course based on the fuzzy restrictions on $O$. Fuzzy scores, $F_{r i}$ and course acronyms are indicated similar to figure 3. 
Figure 5 Hierarchical structure of linguistic variable $\mathbf{O}$

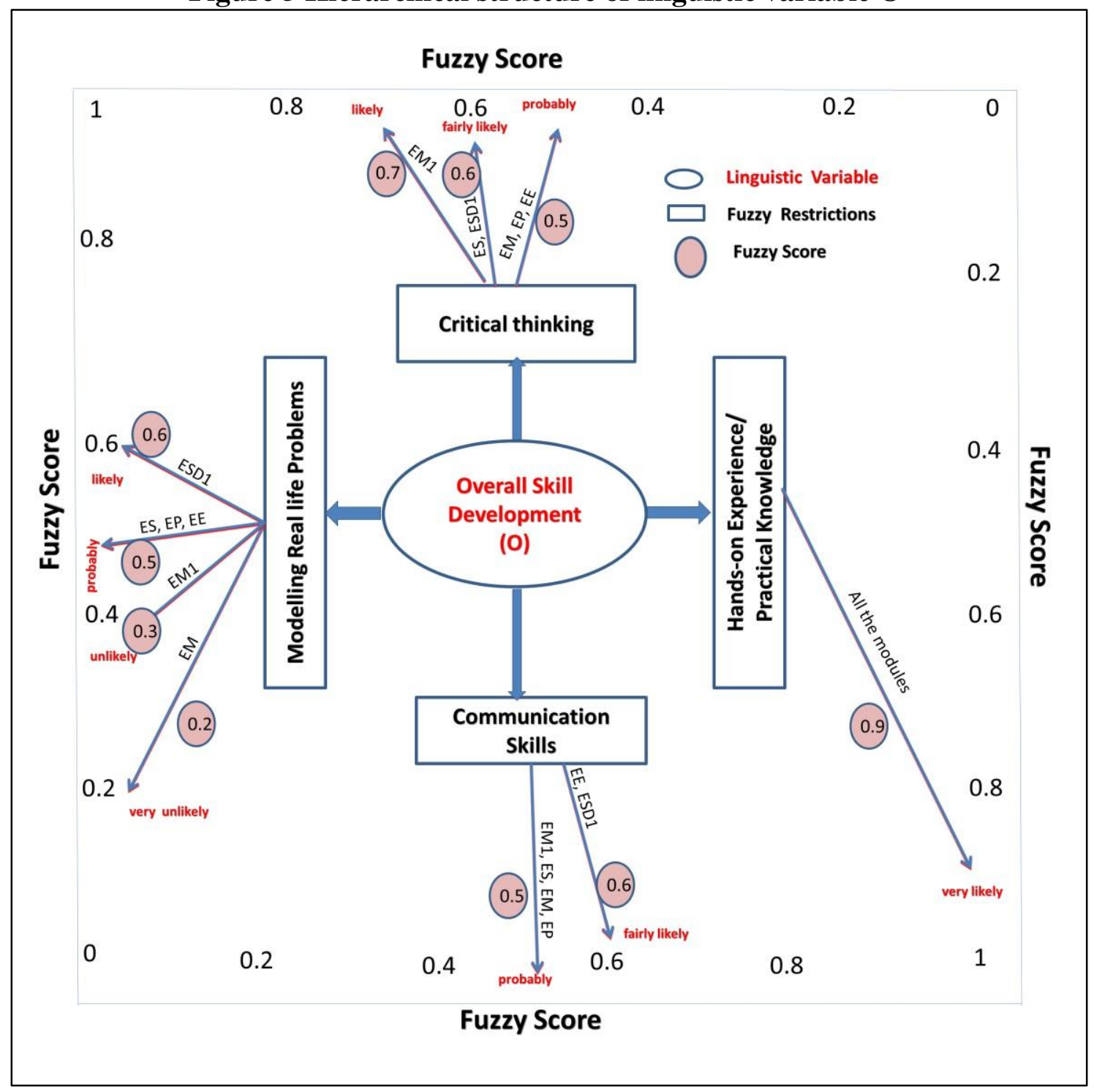

For $O$, the fuzzy set was created based on how the practical and workshop activities were conducted for the first year engineering courses. The degree of membership was assigned by mapping the fuzzy set value to the probability value as indicated in table 4 . A certain event is bound to occur and hence gets a fuzzy score equal to 1 . In contrast, if an event is not possible, the fuzzy score allocated is 0 . Similarly other outcomes of an event is been assigned corresponding to the fuzzy set. For example, EM1 course was not designed to include simulation of mathematical modeling using computer aided tools, hence it is unlikely to develop practical knowledge of the students, this event scores 0.3 in table 5 . On the other hand, all courses included activities to gain some hands-on experience, hence they score very high while mapping the fuzzy subset (very likely) to fuzzy score 0.9 . 
Table 4 Summary of fuzzy scores corresponding to the linguistic variable, 0

\begin{tabular}{|c|c|c|c|c|c|c|c|}
\hline $\begin{array}{c}\text { Oyerall Personal } \\
\text { Development } \\
(O\end{array}$ & $\begin{array}{c}\text { Courses } \\
\text { UActievitidesn }\end{array}$ & $\begin{array}{c}\text { EM1 } \\
\text { Pnactissal }\end{array}$ & $\begin{array}{c}\text { ES } \\
\text { Panadtiabl } \\
(\mathrm{P} \& \mathrm{~L})\end{array}$ & $\begin{array}{l}\text { EM } \\
\text { P\&L }\end{array}$ & $\begin{array}{c}\text { EP } \\
\text { P\&L }\end{array}$ & $\begin{array}{c}\mathrm{EE} \\
\mathrm{P} \& \mathrm{~L}\end{array}$ & $\begin{array}{c}\text { ESD1 } \\
\text { P\&L }\end{array}$ \\
\hline $\begin{array}{l}\qquad\left(u_{i}\right) \\
\text { Communication } \\
\text { skills }\end{array}$ & $\begin{array}{l}\text { Poster/Project } \\
\text { presentation, } \\
\text { Writing Report }\end{array}$ & probably & probably & probably & probably & $\begin{array}{l}\text { Fairly } \\
\text { likely }\end{array}$ & $\begin{array}{l}\text { Fairly } \\
\text { likely }\end{array}$ \\
\hline $\begin{array}{cc}(F) & \text { Fuzzy } \\
\text { score } & \\
& \\
u i & \\
\end{array}$ & & 0.5 & 0.5 & 0.5 & 0.5 & 0.6 & 0.6 \\
\hline $\begin{array}{l}\text { Practical } \\
\text { Knowledge } \quad\left(k_{i}\right)\end{array}$ & $\begin{array}{l}\text { Mathematical } \\
\text { modeling using } \\
\text { computer-aided }\end{array}$ & unlikely & probably & $\begin{array}{c}\text { very } \\
\text { unlikely }\end{array}$ & probably & probably & $\begin{array}{l}\text { Fairly } \\
\text { likely }\end{array}$ \\
\hline $\begin{array}{ll}(F) & \text { Fuzzy } \\
& \text { Score } \\
k i & \end{array}$ & & 0.3 & 0.5 & 0.2 & 0.5 & 0.5 & 0.6 \\
\hline $\begin{array}{l}\text { (c) Critical } \\
\text { Thinking }\end{array}$ & $\begin{array}{l}\text { Solving open ended } \\
\text { problem }\end{array}$ & likely & $\begin{array}{l}\text { fairly } \\
\text { likely }\end{array}$ & probably & probably & probably & $\begin{array}{l}\text { Fairly } \\
\text { likely }\end{array}$ \\
\hline $\begin{array}{c}i \\
\text { Fuzzy Score } \\
(F) \\
c i \\
\end{array}$ & & 0.7 & 0.6 & 0.5 & 0.5 & 0.5 & 0.6 \\
\hline \begin{tabular}{l}
\multicolumn{2}{c}{ Hands-on } \\
Experience \\
Practical \\
Knowledge $\quad\left(h_{i}\right)$
\end{tabular} & $\begin{array}{l}\text { Using lab } \\
\text { equipment and } \\
\text { tools for solving a } \\
\text { given problem }\end{array}$ & $\begin{array}{l}\text { very } \\
\text { likely }\end{array}$ & $\begin{array}{l}\text { very } \\
\text { likely }\end{array}$ & $\begin{array}{l}\text { very } \\
\text { likely }\end{array}$ & $\begin{array}{l}\text { very } \\
\text { likely }\end{array}$ & $\begin{array}{c}\text { very } \\
\text { likely }\end{array}$ & $\begin{array}{l}\text { very } \\
\text { likely }\end{array}$ \\
\hline $\begin{array}{c}\text { Fuzzy Score } \\
F\end{array}$ & & 0.9 & 0.9 & 0.9 & 0.9 & 0.9 & 0.9 \\
\hline
\end{tabular}

All the mapped probabilities of the fuzzy restrictions on the linguistic variable $\mathrm{O}$ are based on the probability assignment given to the fuzzy subsets as indicated in figure 6 and they are tabulated in table 5. Assuming all the fuzzy restrictions are independent to the each other, the corresponding probabilities can be multiplied to calculate the fuzzy scores of each $O_{i}$. This can be formulated as follows.

$$
O_{i}=\prod \boldsymbol{F}_{\boldsymbol{r i}}
$$

$$
\text { where } r \in\{c, h, k, u\}
$$


Figure 6 Mapping between fuzzy set and fuzzy score for linguistic variable $O$

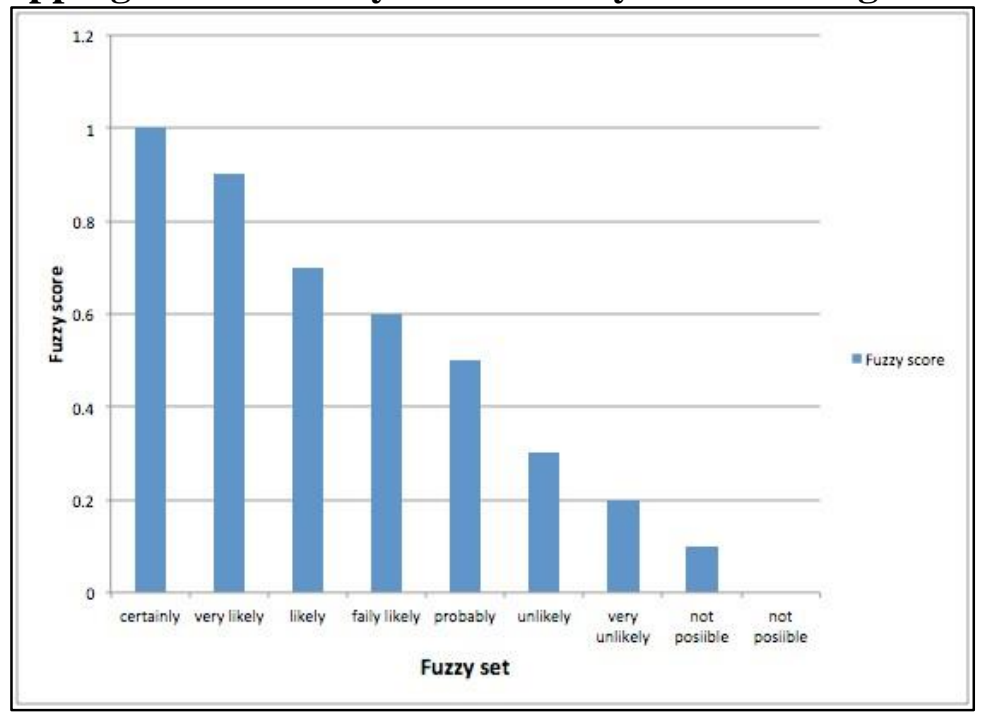

Table 5 Summary of fuzzy scores corresponding to the Interest of students, $I$

\begin{tabular}{|c|c|c|c|c|c|c|}
\hline $\begin{array}{l}\text { Interest of } \\
\text { Students () }\end{array}$ & $\begin{array}{c}E M 1 \\
(i=1)\end{array}$ & $\begin{array}{c}E S \\
(i=2)\end{array}$ & $\begin{array}{c}E M \\
(i=3)\end{array}$ & $\begin{array}{c}E P \\
(i=4)\end{array}$ & $\begin{array}{c}E \boldsymbol{E} \\
(\boldsymbol{i}=\mathbf{5})\end{array}$ & $\begin{array}{c}E S D 1 \\
(i=6)\end{array}$ \\
\hline $\begin{array}{c}\text { Feedback on assignment per } \\
\text { week }\left(a_{i}\right)\end{array}$ & $\begin{array}{c}\text { Bi- } \\
\text { weekly }\end{array}$ & $\begin{array}{c}\text { Bi- } \\
\text { weekly }\end{array}$ & $\begin{array}{c}\text { Bi- } \\
\text { weekly }\end{array}$ & $\begin{array}{c}\text { Bi- } \\
\text { weekly }\end{array}$ & $\begin{array}{c}\text { Bi- } \\
\text { weekly }\end{array}$ & Weekly \\
\hline Fuzzy Score $\left(F_{a i}\right)$ & 0.5 & 0.5 & 0.5 & 0.5 & 0.5 & 1 \\
\hline Coursework $\left(w_{i}\right)$ & $70 \%$ & $50 \%$ & $60 \%$ & $60 \%$ & $60 \%$ & $100 \%$ \\
\hline Fuzzy Score $\left(F_{w i}\right)$ & 0.7 & 0.5 & 0.6 & 0.6 & 0.6 & 1 \\
\hline Summative written Exam $\left(e_{i}\right)$ & $30 \%$ & $50 \%$ & $40 \%$ & $40 \%$ & $40 \%$ & $0 \%$ \\
\hline Fuzzy Score $\left(F_{e i}\right)$ & 0.3 & 0.5 & 0.4 & 0.4 & 0.4 & 0 \\
\hline
\end{tabular}

\subsection{Interest of Students}

The interest and engagement of students to learn and do well in a particular course have a direct impact on performance in that course. Here, linguistic variable, $\mathrm{I}_{\mathrm{i}} \mathrm{is}$ used to highlight the interest of students and will model how students' performance is dependent on his/her interest in a particular course.

Weekly feedback on assignments and frequent formative exams engage students and provide the environment necessary to generate and maintain interest. A summative final exam at the end of course necessitates students to study the course material at the end of the session. In contrast, a continuous assignment and frequent feedback process assist students to focus more on trying different ways to solve a given a problem and in effect make the course more interesting for them even though the load is substantially increased on academic and technical staff. 
Figure 6 gives the hierarchal structure of linguistic variables, $I$. Fuzzy restrictions can be defined by the following set where $r \in\{a, w, e\}$. The fuzzy set values such as weekly, bi-weekly, $40 \%$ are indicated at the arrow end of thin arrows for each course based on the fuzzy restrictions on $I$. Fuzzy scores, $F_{r i}$ and course acronyms are indicated close to the arrows similar to figure 4 . The fuzzy scores for I, is given in the Table 6 .

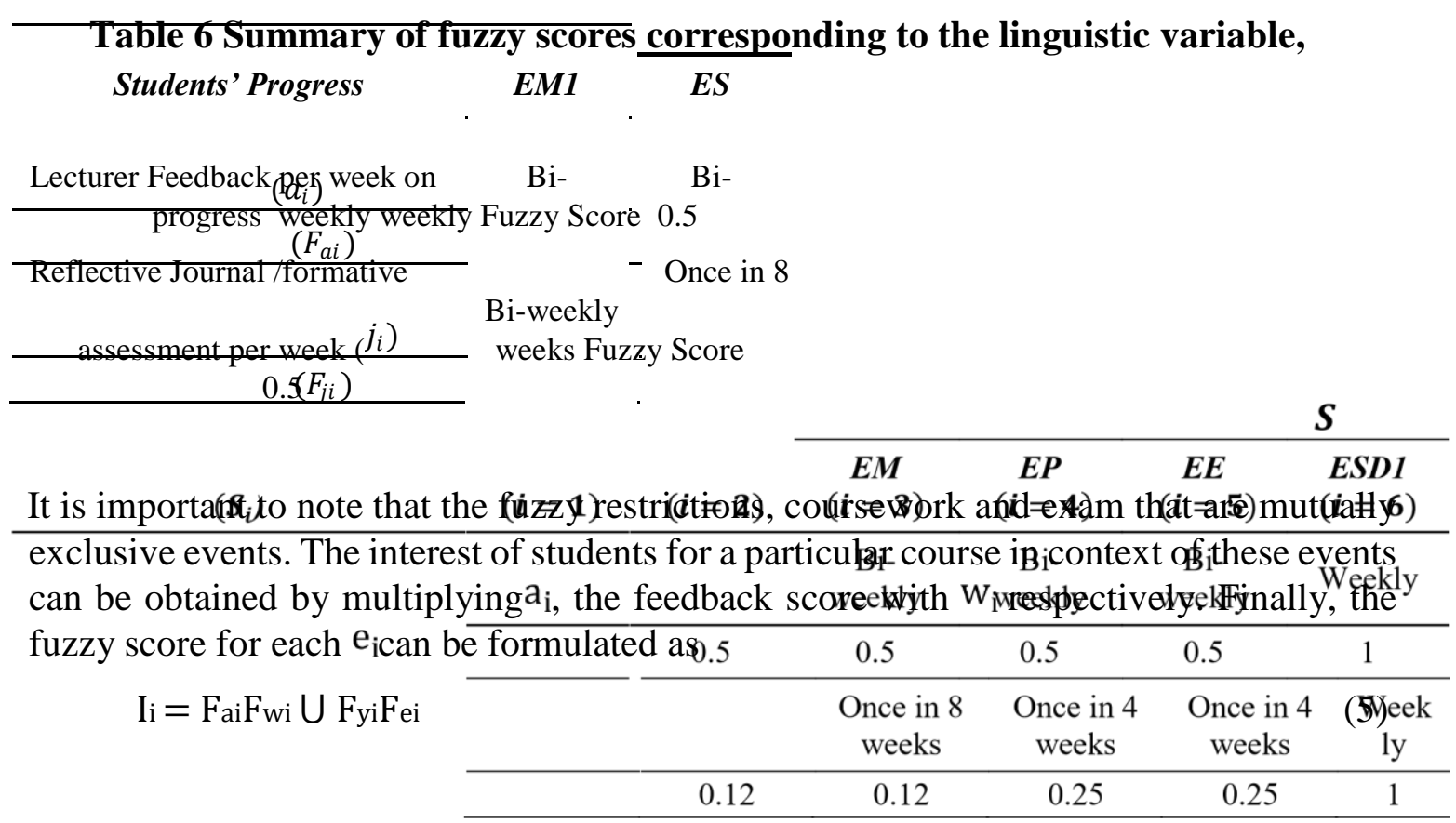

where $F_{y i}$ is the weekly feedback related to the final exam. Typically, feedback on the final exam is not given to individual students, as the students are more interested in passing the course rather than going through the feedback. No or little feedback makes the second term $\mathrm{F}_{\mathrm{yi}} \mathrm{F}_{\text {ei }}$ negligible. Hence, $\mathrm{I}_{\mathrm{i}}$ can be calculated as follows:

$$
\mathrm{I}_{\mathrm{i}}=\mathrm{F}_{\mathrm{ai}} \mathrm{F}_{\mathrm{wi}}
$$

\subsection{Feedback on Students' Progress}

One of the major problems facing many undergraduate schools today [Orsmond, 2009] is that students require frequent and regular feedback. But the number of students is increasing and teachers, who also have research obligations, take longer to provide feedback and also provide less feedback per student. Students often receive limited feedback during a particular course so that their experience is one of blind learning [Hattie, 2007]. They submit work, and before receiving feedback submit further work, and this continues until they receive a suite of grades about which they can do nothing because that course is complete, not only are they deprived of the opportunity to make use of the feedback because the course has finished, they often wouldn't know how to improve their work even if they had been given the chance. To overcome this ESD1 was designed to provide weekly feedback with comprehensive comments to every student. 
ESD1 reflective journals composed by students every week and promptly marked and assessed aim to continuously update students' knowledge in the subject.

Figure 7 gives the hierarchal structure of feedback on students' progress. Fuzzy restrictions can be defined by the following set where $r \in\{a, j\}$. The fuzzy set values such as weekly and bi-weekly are indicated at the arrow end of thin arrows for each course based on the fuzzy restrictions on I. Fuzzy scores, Fri and course acronyms are indicated close to the arrows similar to figure 4 . The Fuzzy scores for $S$, is given in the Table 7.

Table 7 Calculation of stu

\begin{tabular}{ccccccc} 
& & & \multicolumn{3}{c}{ Table } & \multicolumn{2}{c}{$\boldsymbol{P}_{\boldsymbol{i}}$ using equation } \\
\cline { 3 - 7 } Courses & $\boldsymbol{E}_{\boldsymbol{i}}$ & $\boldsymbol{O}_{\boldsymbol{i}}$ & $\boldsymbol{I}_{\boldsymbol{i}}$ & $\boldsymbol{S}_{\boldsymbol{i}}$ & $\begin{array}{c}\boldsymbol{f}_{\boldsymbol{i}}=\boldsymbol{P}_{\boldsymbol{i}} \\
(\boldsymbol{F u z z y} \text { set) }\end{array}$ & $\begin{array}{c}\text { Normalized } \boldsymbol{N}_{\boldsymbol{i}} \\
\text { (degree of } \\
\text { membership) }\end{array}$ \\
\hline EM1 & 0.75 & 0.09 & 0.35 & 0.5 & 0.0118 & 0.09 \\
\hline ES & 0.55 & 0.13 & 0.25 & 0.5 & 0.0089 & 0.06 \\
\hline EM & 0.54 & 0.04 & 0.15 & 0.5 & 0.0016 & 0.01 \\
\hline EP & 0.54 & 0.11 & 0.3 & 0.5 & 0.0089 & 0.06 \\
\hline EE & 0.69 & 0.13 & 0.3 & 0.5 & 0.013 & 0.1 \\
\hline ESD1 & 0.68 & 0.19 & 1 & 1 & 0.13 & 1 \\
\hline
\end{tabular}


Figure 7 Hierarchical structure of linguistic variable I

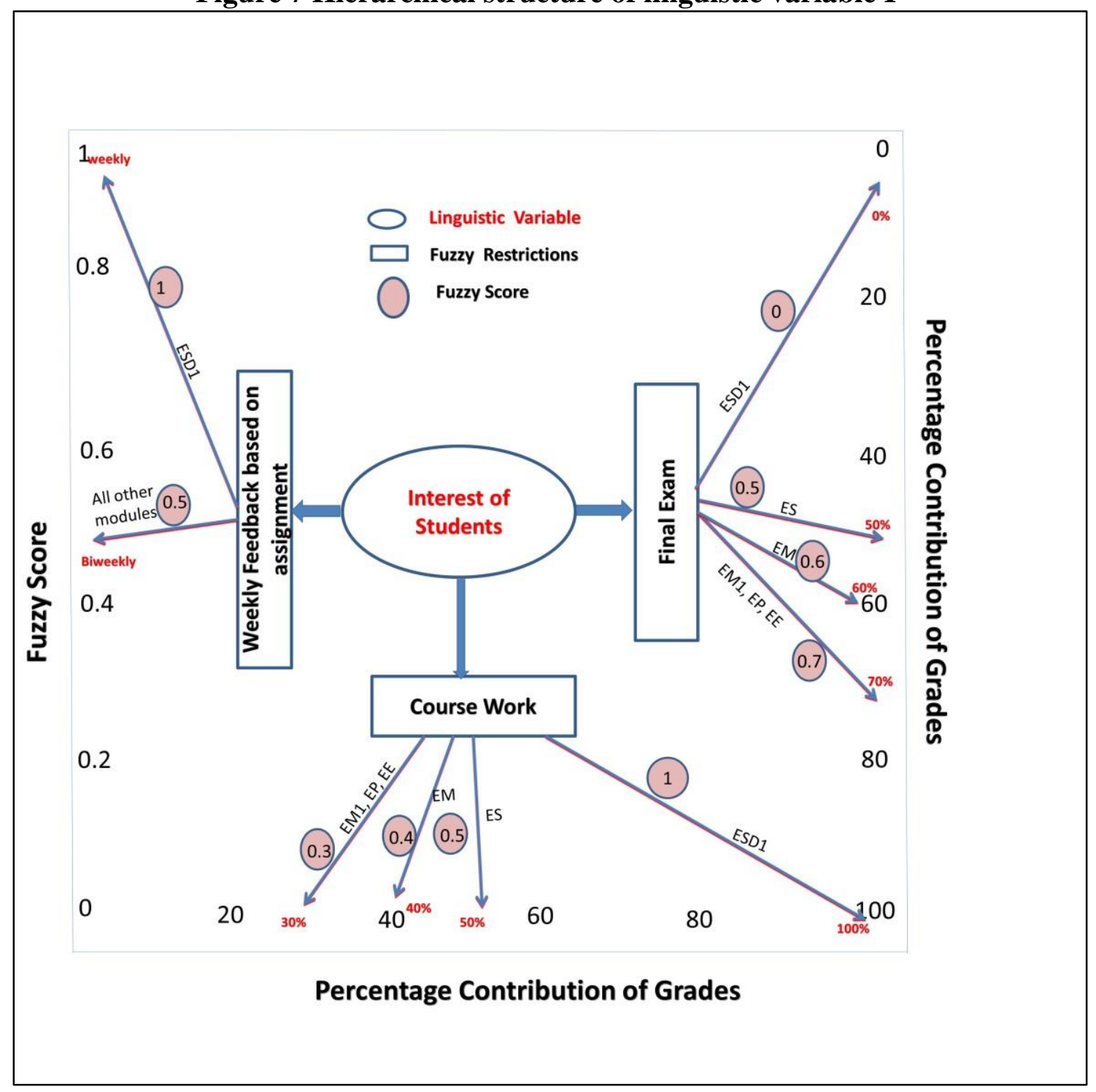

More importantly, either the lecturer feedback or the result of formative assessment gives an indication of students' progress in a particular course. The greater of two fuzzy scores of given fuzzy restrictions can define $\mathrm{S}_{\mathrm{i}}$ for each course. Hence, $\mathrm{S}_{\mathrm{i}}$ can be calculated as follows:

$\mathrm{S}_{\mathrm{i}}=\max \left(\mathrm{F}_{\mathrm{ri}}\right)$

where $r \in\{a, \mathrm{j}\}$

\section{Results and Analysis}

The contents of table 7 highlight the summary of all the fuzzy scores for the linguistic variables, E, O, I and S for each course. Equations 3, 4, 6 and 7 are used for mapping the 
fuzzy set values to their respective fuzzy score (degree of membership). A fuzzy set was then created for $\mathrm{P}_{\mathrm{i}}$ using the Cartesian product of the evaluated fuzzy scores as indicated in equation 8

$$
f_{i}=P_{i}=\sum_{i=1}^{6} E_{i} \times O_{i} \times I_{i} \times S_{i}
$$

Thereafter, a degree of membership is assigned for the fuzzy set obtained for, $\mathrm{P}_{\mathrm{i}}$. This is done by normalizing $\mathrm{P}_{\mathrm{i}}$. The normalized value is denoted as $\mathrm{N}_{\mathrm{i}}$. It can be seen from the table 8 that, the students' performance, $P_{i}$ based on the predictive model gives a high normalized value for ESD1 followed by EE and EM1. The proposed model also gives EM the lowest score due to lack of overall skill development content in the course design. Ideally the ESD1 course scores high due to its focus on activities related weekly feedback and tracking the students' interest in course. Our prediction shows that in context of students' performance, the ESD1 course design is at least 10 times better than any other course delivered in first year of Engineering (figure 8).

Table 8 Comparison of Predictive Score Vs Actual Score

\begin{tabular}{ccc}
\hline Courses & $\begin{array}{c}\text { Normalized Predicted } \\
\text { Students Performance }\left(\boldsymbol{N}_{\boldsymbol{i}}\right)\end{array}$ & $\begin{array}{c}\text { Percentage of students } \\
\text { scored } 70 \text { and above }\left(\boldsymbol{M}_{\boldsymbol{i}}\right)\end{array}$ \\
\hline EM1 & 0.09 & $0.25(25 \%)$ \\
\hline ES & & $0.38(38 \%)$ \\
\hline EM & $0.05(5 \%)$ \\
\hline EP & $0.22(22 \%)$ \\
\hline EE & 1 & $0.24(24 \%)$ \\
\hline ESD1 & 0.06 & $0.7(70 \%)$ \\
& 0.01 & \\
& 0.06 & \\
& 0.1 &
\end{tabular}


Figure 8 Hierarchical structure of linguistic variable S

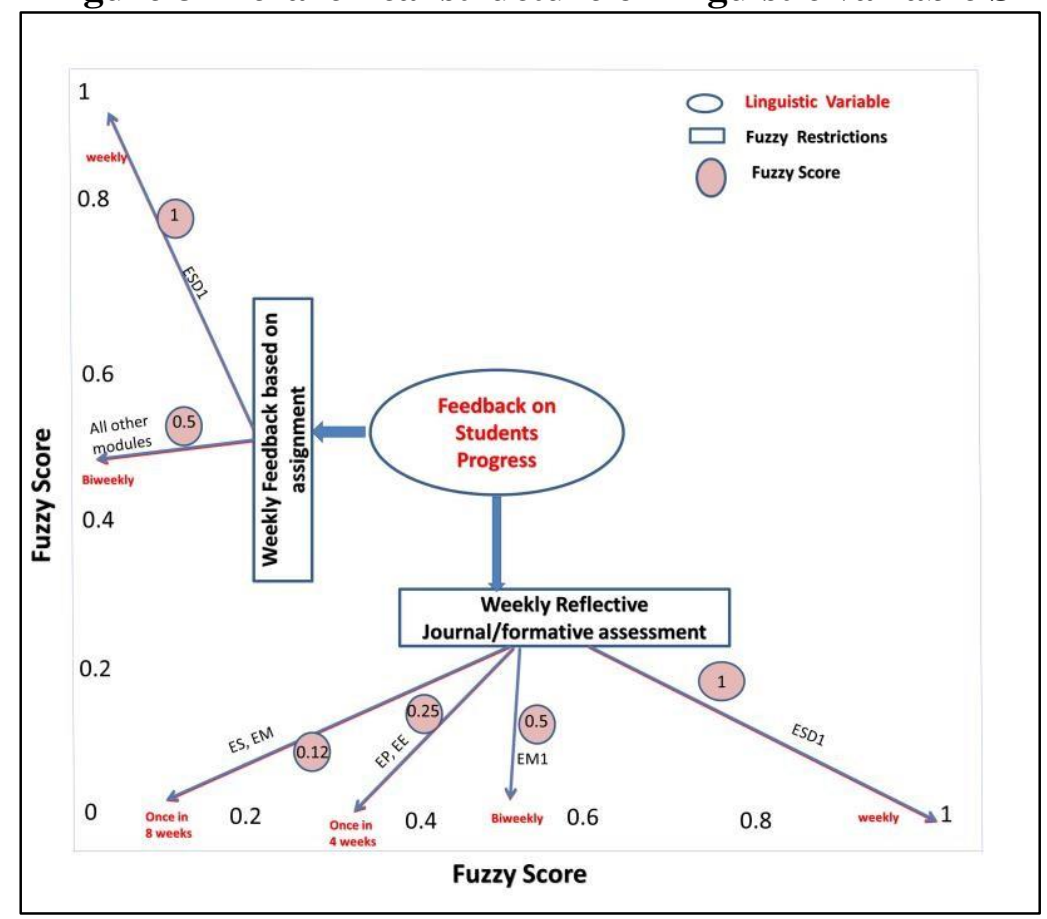

A comparison is carried out between the predicted students' performance $\mathrm{N}_{\mathrm{i}}$ and the actual grades of students scored in the first year of engineering. 242 students were enrolled in the first year of engineering and 40 academic staff members including lecturers, instructors and technicians were involved in developing, reviewing and delivery of the content of the course. For this comparison, the actual grades, $M_{i}$ for students who got A (70\% and above) in respective courses were compared with the normalized, $\mathrm{N}_{\mathrm{i}}$ as tabulated in table 8 . For example, $70 \%$ of students secured grade $\mathrm{A}$ in ESD1 and in comparison we predicted that all the students would score more than $70 \%$ in ESD1 because of its design oriented PBL methodology.

Figure 9 shows a comparison between the predicted Students' Performances $\left(\mathrm{N}_{\mathrm{i}}\right)$ and grade based students' performance $\left(\mathrm{M}_{\mathrm{i}}\right)$, these were plotted for each course. The graph clearly shows that the there is a high correlation between the predicted students' performance and the actual grades. There is a slight jump in the actual marks of ES, however, this jump can be explained by the fact that this course has the highest contribution of coursework after ESD1. A low score in EM is the result of nonengagement of students in lectures and tutorials and lack of students' interest in the course. EE and EM1 courses show the best performance second to ESD1 as predicted by the proposed fuzzy model. 
Figure 9 Graph showing comparison of students' performance and students' grade

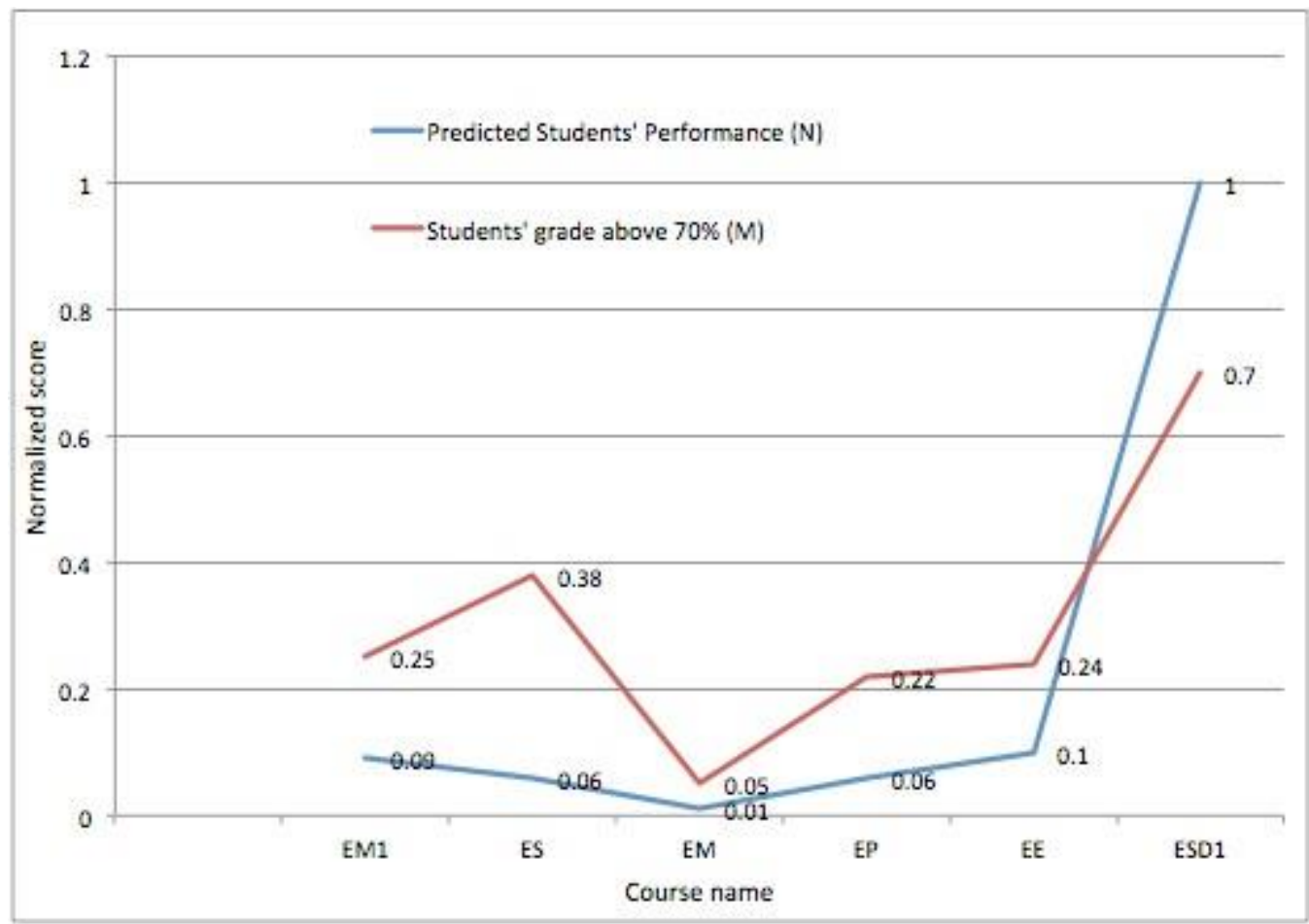

To measure the strength of correlation between $\mathrm{N}$ and $\mathrm{M}$, we calculated linear correlation coefficient, $\mathrm{r}^{\prime}$, commonly known as Pearson product moment correlation. The mathematical formula for $r^{\prime}$ is

$$
\mathrm{r}^{\prime}=\frac{\mathrm{n}\left(\sum \mathrm{NM}\right)-\left(\sum \mathrm{N}\right)\left(\sum \mathrm{M}\right)}{\sqrt{\left[\mathrm{n} \sum \mathrm{N}^{2}-\left(\sum \mathrm{N}\right)^{2}\right]\left[\mathrm{n} \sum \mathrm{M}^{2}-\left(\sum \mathrm{M}\right)^{2}\right]}} \quad-1 \leq \mathrm{r}^{\prime} \leq 1
$$

where $n$ is the number of courses. Given two variables $\mathrm{x}$ and $\mathrm{y}$,

$\mathrm{r}^{\prime}=+1 \stackrel{\text { yields }}{\longrightarrow}$ perfect positive corelation between $\mathrm{x} \& \mathrm{y}$ In general, for positive $\mathrm{r}^{\prime}=-1 \stackrel{\text { yields }}{\longrightarrow}$ perfect negative corelation between $\mathrm{x} \& \mathrm{y} \quad \begin{array}{ll}\text { correlation, } & \mathrm{r}^{\prime}>0.8 \text { is } \\ \text { considered } & \text { strong and }\end{array}$

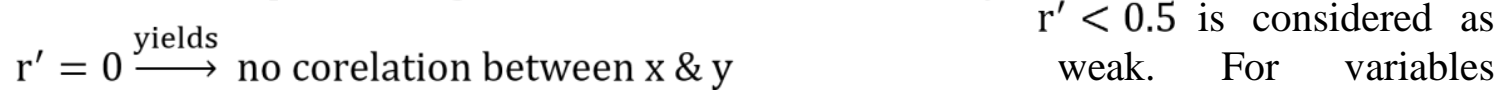
$\mathrm{N}$ and $\mathrm{M}, \mathrm{r}^{\prime}>0.89$. Hence, $\mathrm{N}$ and Mare strongly correlated. This further validates that the measured students' performance using the proposed predictive model is highly reliable in context with students' grade. 


\section{Conclusion}

An effective predictive fuzzy model for students' performance at first year of engineering degree is presented. A set of four linguistic variables including, students engagement in lectures and tutorials, overall skills development, interest of students and feedback frequency, were introduced with their hierarchal structure. Fuzzy classification of the fuzzy sets was established for each linguistic variable based on the fuzzy restrictions. A mapping was carried out to measure the degree of membership (fuzzy scores) for each fuzzy set. With the assumption that all the linguistic variables are independent, a cartesian product was used to evaluate the students' performance. Following comparison with the actual first year engineering students' performance, it was observed that there is a strong positive correlation between the actual and predicted results. Hence, it can be concluded that; first, the integration of project based learning in course contents such as in ESD1, develop students' skills and encourage them to work on innovative ideas, think critically and significantly improves their overall performance. Second, the proposed predictive fuzzy model can be used to predict students' performance. Finally, the work initiated will hopefully lead to further improvements of the proposed model by integrating linguistic variables related to cultural factors, globalization of technology and financial restrictions.

\section{References}

Connor, A.M., Karmokar, S. and Whittington C. (2015), Strategies for Enhancing Engineering and Technology Education, International Journal of Engineering Pedagogy, Vol. 5 No. 2

Albanese, M. A. and Mitchell, S. (1993). Problem-based learning: a review of literature on its outcomes and implementation issues. Acad. Med. 68, 52-81.

Barrows, H.S. (1996). Problem-based Learning in medicine and beyond: A brief overview. New Directions for Teaching and Learning, 1996(68), 3-12 http://dx.doi.org/10.1002/t1.37219966804

Wilkinson, N. (2005), Managerial Economics: A problem solving Approach, Cambridge University Press.

Sabag, I., Trotskovsky, E. and Waks, S. (2014), Engineering design projects as a reflection promoter, European Journal of Engineering Education Vol. 39. No. 3

Zadeh, L. A., (1994), Fuzzy logic, neural networks, and soft computing, Communications of the ACM Mar.

Stachowicz, M.S., and Kochanska, M.E., (1987), Fuzzy modeling of the process, Proc. of Second International Fuzzy Systems Association Congress, Tokyo. 
Pedrycz W., (1996), Fuzzy modeling paradigms and practice, Kluwer Academic Publisher, Boston

Babus `ka, R., (1998), Fuzzy Modeling for Control, Kluwer Academic Publishers, Boston.

Abonyi, J., and Babus `ka, R., (2000), Local and global identification and interpretation of parameters in Takagi-Sugeno fuzzy models. In Proceedings 9th IEEE International Conference on Fuzzy Systems FUZZ-IEEE 2000; San Antonio, TX, May 2000, pp 835840 .

Zadeh, L.A., (1975), the concept of a linguistic variable and its application to approximate reasoning - I, Information Sciences 8, 199 -249

Woods, D.R., Felder, R.M., Rugarcia, A. and Stice, J.E., (2000) The future of engineering education III. Developing critical skills. Chemical Engineering Education, 34, 2, 108 117

McAdams D.P, and Olson B.D., (2010), Personality Development: Continuity and Change Over the Life Course, Annual Review of Psychology Vol. 61: 517-542

Orsmond, P and Merry, S (2009) Processing tutor feedback: a consideration of qualitative differences in learning outcomes for high and non-high achieving students. Paper presented at the Fostering Communities of Learners, 13th EARLI Conference, Amsterdam, 25-29 August 2009.

John Hattie and Helen Timperley, (2007) The Power of Feedback. Review of Educational Research, Vol. 77, No. 1, pp. 81-112, DOI: 10.3102/003465430298487 March. 